\title{
Radiation Risk Communication by Nurses
}

\author{
Takumi Yamaguchi*, RN, PHN, PhD \\ Radiation Emergency Medicine Research Center, Nuclear Safety Research Association, Shimbashi 5-18-1, Minato-City, Tokyo 105-0004, Japan
}

${ }^{\star}$ Corresponding author: Takumi Yamaguchi, Radiation Emergency Medicine Research Center, Nuclear Safety Research Association, Shimbashi 5-18-1, Minato-City, Tokyo 105-0004, Japan; Tel: +81-3-5470-1982; Fax: +81-3-5470-1978; Email: yamaguchi@nsra.or.jp

Received: January 21, 2022; Accepted: January 26, 2022; Published: February 10, 2022

\begin{abstract}
Risk communication is defined by the National Research Council as an interactive process of exchange of information and opinion among individuals, groups, and institutions. Experts do not push risk information on the people involved, but the expert assumes the role of presenting all the options to those involved, carefully explaining the advantages and disadvantages of the options, and then discussing them based on that explanation. After the Fukushima Daiichi Nuclear Power Station disaster, radiation risk communication initiatives were launched using the risk communication approach. Many residents were anxious not only about radiation health risks but also their whole health, including mental illness and lifestyle-related diseases. Thus, nurses play an important role as radiation risk communicators because they can practice radiation risk communication as part of a health consultation. However, nurses in Japan have not been educated about radiation, thus they have anxiety about radiation. To get consultation from those who have radiation anxiety, nurses must have some minimum knowledge on radiation. Similarly, the education of specialists in the field of radiation risk communication is essential and urgent.
\end{abstract}

\section{What is Risk Communication?}

Risk communication is defined by the National Research Council as an interactive process of exchange of information and opinion among individuals, groups, and institutions [1]. "Interactive" does not refer to one-way communication from experts from central and/or municipal governments, companies, and scientists, but rather to many individuals, affiliates, and institutions discussing issues and opinions about risk, i.e., exchanging risk information and coming to a decision among those involved [2]. The most important component in risk communication is to not impose an opinion, but to discuss among the various individuals involved, and then use various measures to arrive at the best decision. Thus, the expert assumes the role of presenting all the options to those involved, carefully explaining their advantages and disadvantages, and then discussing them based on that explanation. In general, there are several phases of risk communication. These are: "raising awareness about the problem," "providing and sharing information," "discussing and co-considering," "building trust," "stimulating behavioral change," and "building consensus" [3-5] (Figure 1).

Specifically, in "raising awareness about the problem" and "providing and sharing information" the goal is to get the information to those involved through lectures and printed materials. Recently, there have also been reports on the effectiveness of risk communication through lectures using web meeting systems [5], quartet games, and other games used in class to acquire knowledge [6]. However, if the audience is not interested in the information in the first place, there is a high possibility that it will not reach them. Moving to the

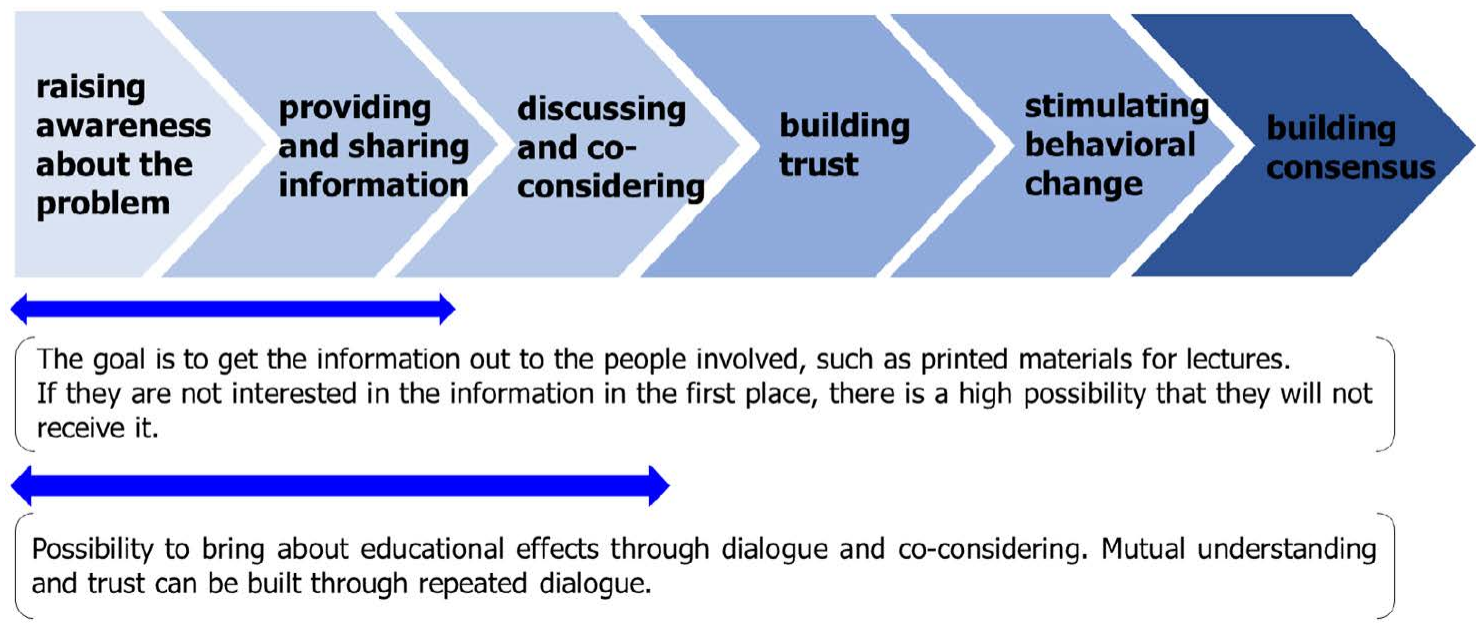

Figure 1: Phase of risk communication. 
"discussing and co-considering" phase, this phase should bring about more educational effects by allowing discussion with those involved while co-considering and interacting with them. Furthermore, if we move to the "building trust" phase in the course of repeated dialogues, those involved trust the communicator, and the communicator trusts them, leading to a mutual understanding and trust that should further stimulate risk communication discussions. From this phase of risk communication, we can move to the "stimulating behavioral change" and "building consensus" phases. Risk communication is established through these phases and the processes of dialogue, co-consideration, and collaboration. Therefore, it is important to emphasize and practice "individuality" and "trust" [7].

\section{What is Radiation Risk Communication?}

Since the 1986 Chernobyl nuclear power plant accident and that of the 2011 TEPCO Fukushima Daiichi Nuclear Power Station, radiation risk communication has received special attention [8,9]. Radiation risk communication has been targeted at patients undergoing medical radiotherapy and examinations; since the Fukushima Daiichi Nuclear Power Station accident, however, it has been increasingly used in the field of public health. Specifically, after the Fukushima Daiichi accident in 2011, the government announced a policy on radiation risk communication [10], and it is now being practiced more actively. However, until then, radiation experts did not have any knowledge about risk communication, creating a gap between the experts and the people involved [11].

\section{Radiation Risk Communication after the Fukushima Disaster for Fukushima Residents}

Immediately after the accident, the International Commission on Radiological Protection (ICRP), which had gained experience from the Chernobyl disaster, launched dialogues with local residents [12] and specialists from universities, which had been conducting research on radiation for a long time, practiced risk communication [13-15]. Thereafter, Japan's Ministry of the Environment created a facility called the "Radiation Risk Communication Counselor Support Center," and a system to support local government officials in dealing with residents was established [16]. As a result, it has been reported that the perception of radiation risk among people of the Fukushima Prefecture is improving [17] through the implementation of radiation risk communication by international organizations, universities, research institutes, and central government agencies to local residents, and we believe that certain results have been achieved. Ten years after the accident, many residents have gained knowledge about radiation and seem to have overcome their radiation anxiety; however, latent anxiety remains, which may manifest itself when the topic of radiation is raised. For example, in the aftermath of Typhoon Hagibis in 2019, anxiety rose around concerns that radioactive materials, which had adhered to the soil may have migrated into living spaces [18]. As 10 years have passed since the accident, the degree and causes of anxiety have become different for each individual, and a more individualized approach is becoming necessary. In addition, as each individual's opinion grows more fixed and complicated, it is necessary to build a relationship of trust to approach them and to continue to respond to them over a long period.

\section{Radiation Risk Communication after the Fukushima Disaster for Evacuees Living Outside of Fukushima Prefecture}

As of December 2021, the number of evacuees from Fukushima Prefecture was reported to be about 27,000 nationwide, and many Fukushima residents are still living outside of the prefecture [19]. Eleven years will soon have passed since the accident, and although many residents have moved from "evacuation" to "migration," there are also those who are living outside of Fukushima Prefecture with feelings for their hometowns. It is estimated that people living outside the Fukushima Prefecture have less information about radiation than those living in it, and that there have been no improvements in radiation risk perception based on correct knowledge - there are many people who still misperceive radiation risks. For instance, evacuees from outside the prefecture often evacuate multiple times, moving from one place to another in the prefecture, and then evacuating to the Kanto region, making it difficult for the local governments where they lived before the accident to keep track of them. As a result, evacuees have not been approached, and residents who want to return to their hometowns often find themselves in an isolated state. These evacuees form communities with fellow evacuees, and psychologists and other professionals support these communities, but radiation specialists rarely intervene. Thus, when a radiation expert nurse practiced risk communication, evacuees raised questions about the situation in Fukushima Prefecture based on misperceptions, and it was assumed that information was not reaching them and that their perceptions were fixed (Figure 2).

\section{Do Nurses Play a Role as Risk Communicators after Nuclear/ Radiation Disaster?}

Previous reports have suggested that nurses are the most appropriate professionals to lead radiation risk communication [20,21]. This is because nurses, who look after the whole person's health, are able to assess each person individually and provide the necessary information. Since the nuclear accident, it has become clear that the rate of mental illness and lifestyle-related diseases among Fukushima residents is increasing $[17,22]$, and it was considered that nurses have the advantage of being able to implement radiation risk communication as part of health counseling. However, nurses in Japan are not educated about

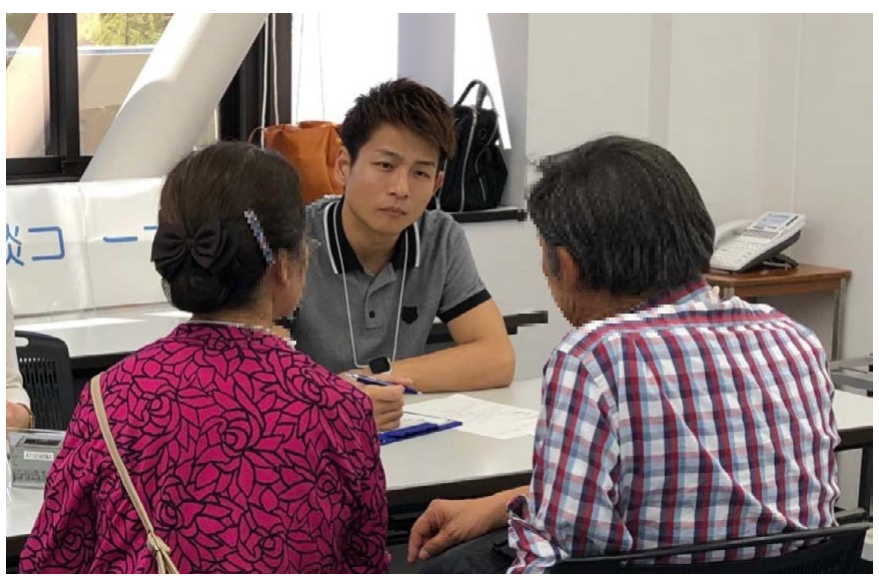

Figure 2: Radiation risk communication with evacuees by specialists in the field of radiation risk communication. 
the health effects of radiation during their nursing studies. As a result, reports indicate that many nurses have little knowledge on radiation, and it has been shown that nurses themselves have anxiety about radiation [23]. Therefore, it is necessary to provide radiation education in the incumbent education of nurses and to equip them with the knowledge and skills needed to practice radiation risk communication. Furthermore, along with the dissemination of knowledge on radiation and education on risk communication to general nurses, there is an urgent need to train nurses who can respond in a more specialized manner. In Japan, the education of certified nurse specialists (CNS) in radiological nursing has begun [24], and it is hoped that these nurses will have a high level of knowledge on radiation to deal with more difficult cases and will be available to consult with general nurses about radiation risk communication.

According to a study by the Mitsubishi Research Institute (MRI), about half of Tokyo residents believe that the Fukushima accident will cause delayed effects, such as cancer, in people living in the Fukushima Prefecture, and/or that there will be hereditary effects on their children and grandchildren [25]. Many people misunderstand the radiation health risks and situation of the Fukushima Prefecture after the nuclear disaster. Since such misperceptions may lead to discrimination and prejudice, nurses need to play a role in individualizing risk communication to those who are concerned about radiation.

\section{Conclusion}

Risk communication has several phases, and its effect differs by phase. Thus, it is necessary to plan and implement risk communication by considering the content based on the type of target and the purpose of the communication. After a nuclear disaster, radiation risk communication plays an important role in relieving those affected and reducing radiation health anxiety. In the wake of the Fukushima Daiichi nuclear disaster, many people were anxious not only about the health effects of radiation but also that of the whole person. Thus, nurses who are able to consult on general health and radiation health effects, among others, play an important role as risk communicators. Nuclear disasters are extremely rare, but it is hoped that all nurses acquire the minimum knowledge necessary on radiation health effects due to their role as risk communicators. It is also necessary to educate not only generalists but also specialist nurses.

\section{References}

1. National Research Council Improving Risk Communication. Washington, DC: The National Academies Press (1989).

2. World Health Organization. Risk communications.

3. International Risk Governance Council. IRGC risk governance framework.

4. Consumer Affairs Agency (2016) Japan. Effectiveness of Risk Communication Provided by Dr. Kanagawa.

5. Yamaguchi T, Sekijima H, Naruta S, Ebara M, Tanaka M, et al. Radiation Risk Communication for Nursing Students - The learning effects of an online lecture. The Journal of Radiological Nursing Society of Japan.

6. Yamaguchi T, Horiguchi I (2021) Radiation risk communication initiatives using the "Quartet Game" among elementary school children living in Fukushima Prefecture. Japanese Journal of Health and Human Ecology 87: 274-285.

7. World Health Organization (2017) Communicating risk in public health emergencies: A WHO guideline for emergency risk communication (ERC) policy and practice.
8. Lochard J (2007) Rehabilitation of living conditions in territories contaminated by the Chernobyl accident: The ETHOS project. Health Physics 93: 522-526. [crossref]

9. Yamaguchi I, Shimura T, Terada H, Svendsen ER, Kunugita N (2018) Lessons learned from radiation risk communication activities regarding the Fukushima nuclear accident. Journal of the National Institute of Public Health 67: 93-102.

10. 1Reconstruction Agency (2017) Japan. Strategies for Dispelling Rumors and Strengthening Risk Communication.

11. Kanda R (2014) Risk communication in the field of radiation. Journal of Disaster Research 9: 608-618.

12. International Commission on Radiological Protection ICRP and Fukushima.

13. Takamura N, Orita M, Taira Y, Fukushima Y, Yamashita S (2018) Recovery from nuclear disaster in Fukushima: Collaboration model. Radiation Protection Dosimetry 182: 49-52. [crossref]

14. Tokonami S, Miura T, Akata N, Tazoe H, Hosoda M, Chutima K, et al. (2021) Support activities in Namie Town, Fukushima undertaken by Hirosaki University. Annals of the ICRP 50: 102-108.

15. Murakami M, Sato A, Matsui S, Goto A, Kumagai A, Tsubokura M, et al. (2017) Communicating with residents about risks following the Fukushima nuclear accident. Asia-Pacific Journal of Public Health 29: 74S-89S. [crossref]

16. Ministry of the Environment (2015) Japan 5.1 Status of Implementation of Decontamination Projects.

17. Ministry of the Environment Japan. BOOKLET to Provide Basic Information Regarding Health Effects of Radiation (1st edition).

18. Taira Y, Matsuo M, Yamaguchi T, Yamada Y, Orita M, et al. (2020) Radiocesium levels in contaminated forests has remained stable, even after heavy rains due to typhoons and localized downpours. Scientific Reports 10. [crossref]

19. Fukushima Prefecture. The number of evacuees from Fukushima Prefecture.

20. Sato Y, Hayashida N, Orita M, Urata H, Shinkawa T, et al. (2015) Factors associated with nurses' intention to leave their jobs after the Fukushima Daiichi Nuclear power plant accident. PLOS ONE 10.

21. Yamaguchi T, Orita M, Urata H, Shinkawa T, Taira Y, et al. (2018) Factors affecting public health nurses' satisfaction with the preparedness and response of disaster relief operations at nuclear emergencies. Journal of Radiation Research 59: 240-241.

22. Takahashi A, Ohira T, Okazaki K, Yasumura S, Sakai A, et al. (2020) Effects of psychological and lifestyle factors on metabolic syndrome following the Fukushima Daiichi nuclear power plant accident: The Fukushima health management survey. Journal of Atherosclerosis and Thrombosis 27: 1010-1018. [crossref]

23. Nagatomi M, Yamaguchi T, Shinkawa T, Taira Y, Urata H, Orita M et al. (2019) Radiation education for nurses working at middle-sized hospitals in Japan. Journal of Radiation Research 60: 717-718. [crossref]

24. Nishizawa Y, Noto Y, Ichinohe T, Urata H, Matsunari Y, Itaki C et al. (2015) The framework and future prospects of radiological nursing as advanced practice nursing care. The Journal of Radiological Nursing Society of Japan 3: 2-9.

25. Mitsubishi Research Institute, Inc. Fukushima reconstruction: Current status and radiation health risks.

\section{Citation:}

Takumi Yamaguchi (2022) Radiation Risk Communication by Nurses. Integr J Nurs Med Volume 3(1): 1-3. 